\title{
Identifying (subsurface) anthropogenic heat sources that influence temperature in the drinking water distribution system
}

\author{
Claudia M. Agudelo-Vera ${ }^{1}$, Mirjam Blokker ${ }^{1}$, Henk de Kater ${ }^{2}$, and Rob Lafort ${ }^{2}$ \\ ${ }^{1}$ KWR-Watercycle Research Institute, Nieuwegein, 3430 BB, the Netherlands \\ ${ }^{2}$ EVIDES Waterbedrijf, Rotterdam, $3006 \mathrm{HC}$, the Netherlands \\ Correspondence to: Claudia M. Agudelo-Vera (claudia.agudelo-vera@kwrwater.nl) \\ Received: 17 March 2017 - Discussion started: 21 March 2017 \\ Revised: 17 July 2017 - Accepted: 2 August 2017 - Published: 14 September 2017
}

\begin{abstract}
The water temperature in the drinking water distribution system and at customers' taps approaches the surrounding soil temperature at a depth of $1 \mathrm{~m}$. Water temperature is an important determinant of water quality. In the Netherlands drinking water is distributed without additional residual disinfectant and the temperature of drinking water at customers' taps is not allowed to exceed $25^{\circ} \mathrm{C}$. In recent decades, the urban (sub)surface has been getting more occupied by various types of infrastructures, and some of these can be heat sources. Only recently have the anthropogenic sources and their influence on the underground been studied on coarse spatial scales. Little is known about the urban shallow underground heat profile on small spatial scales, of the order of $10 \mathrm{~m} \times 10 \mathrm{~m}$. Routine water quality samples at the tap in urban areas have shown up locations - so-called hotspots - in the city, with relatively high soil temperatures - up to $7^{\circ} \mathrm{C}$ warmer - compared to the soil temperatures in the surrounding rural areas. Yet the sources and the locations of these hotspots have not been identified. It is expected that with climate change during a warm summer the soil temperature in the hotspots can be above $25^{\circ} \mathrm{C}$. The objective of this paper is to find a method to identify heat sources and urban characteristics that locally influence the soil temperature. The proposed method combines mapping of urban anthropogenic heat sources, retrospective modelling of the soil temperature, analysis of water temperature measurements at the tap, and extensive soil temperature measurements. This approach provided insight into the typical range of the variation of the urban soil temperature, and it is a first step to identifying areas with potential underground heat stress towards thermal underground management in cities.
\end{abstract}

\section{Introduction}

The temperature of the water at customers' taps is largely influenced by the soil temperature $\left(T_{\text {soil }}\right)$ around the drinking water distribution system (DWDS). In the Netherlands it was shown that the water temperature in distribution mains (pipes with a diameter of 60-200 $\mathrm{mm}$, typical residence times of $48 \mathrm{~h}$ or more and located at a depth of $1 \mathrm{~m}$ ) approaches the $T_{\text {soil }}$ around them (Blokker and Pieterse-Quirijns, 2013). Water temperature is an important determinant of water quality, since it influences physical, chemical and biological processes, such as absorption of chemicals, microbial growth and chlorine decay. In the Netherlands drinking water is dis- tributed without an additional residual disinfectant and the temperature of drinking water at customers' taps is not allowed to exceed $25^{\circ} \mathrm{C}$ (Rijksoverheid, 2011). During a warm year, $2006,0.1 \%$ of the routine water quality samples exceeded this norm (Versteegh and Dik, 2007). In the future more samples are expected to exceed this threshold due to (i) climate change and (ii) increasing anthropogenic heat emissions $\left(Q_{F}\right.$; Menberg et al., 2013b). $Q_{F}$ is related to the waste heat resulting from heating and cooling of buildings, manufacturing, transportation, and lighting. Human and animal metabolisms are also considered sources of artificial heat. $Q_{F}$ contributes to the urban heat island (UHI) effect. An UHI is an urban area that is significantly warmer than its 
Table 1. Methods to determine soil or water temperature.

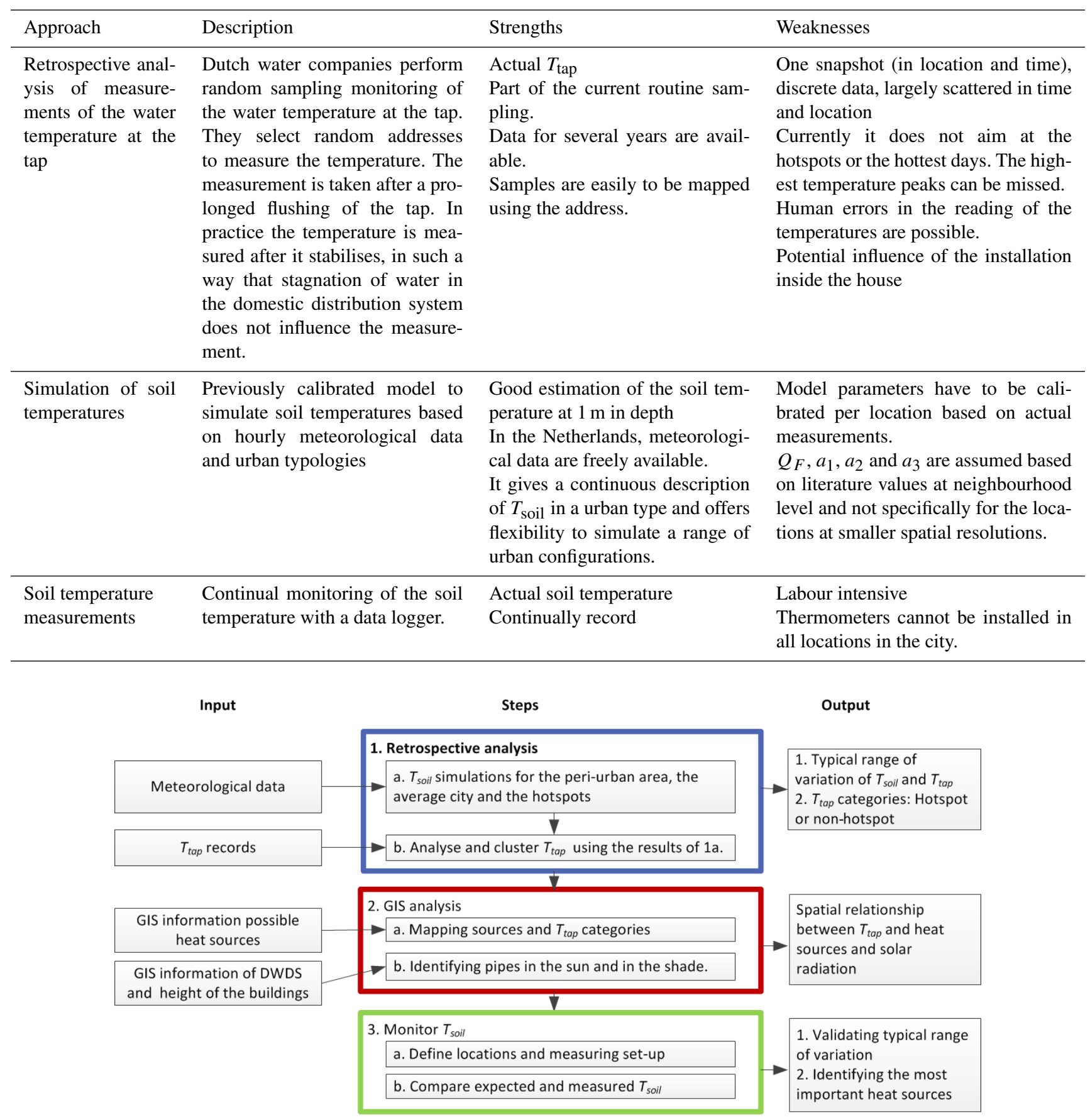

Figure 1. Proposed method to identify heat sources and urban characteristics that locally influence the soil temperature.

surrounding rural areas due to human activities. UHI typically refers to the air temperature, SUHI to the surface urban heat island and SSUHI to the subsurface urban heat island.

Although it is clear that there is a relationship between (sub)surface temperatures and urban development (Grimmond et al., 2010), it is difficult to predict these temperatures on a small spatial scale, i.e. on a grid smaller than
$10 \mathrm{~m} \times 10 \mathrm{~m}$. Currently, thermal remote sensing is used to observe and investigate the SUHI. The daytime SUHI intensity of Rotterdam can be as large as $10^{\circ} \mathrm{C}$, with variations between the different neighbourhoods (Klok et al., 2012). However, these analyses take place at coarse spatial and temporal scales, viz. $1 \mathrm{~km} \times 1 \mathrm{~km}$ over the course of several years (Agudelo-Vera et al., 2015a). Averaging softens the peaks, 


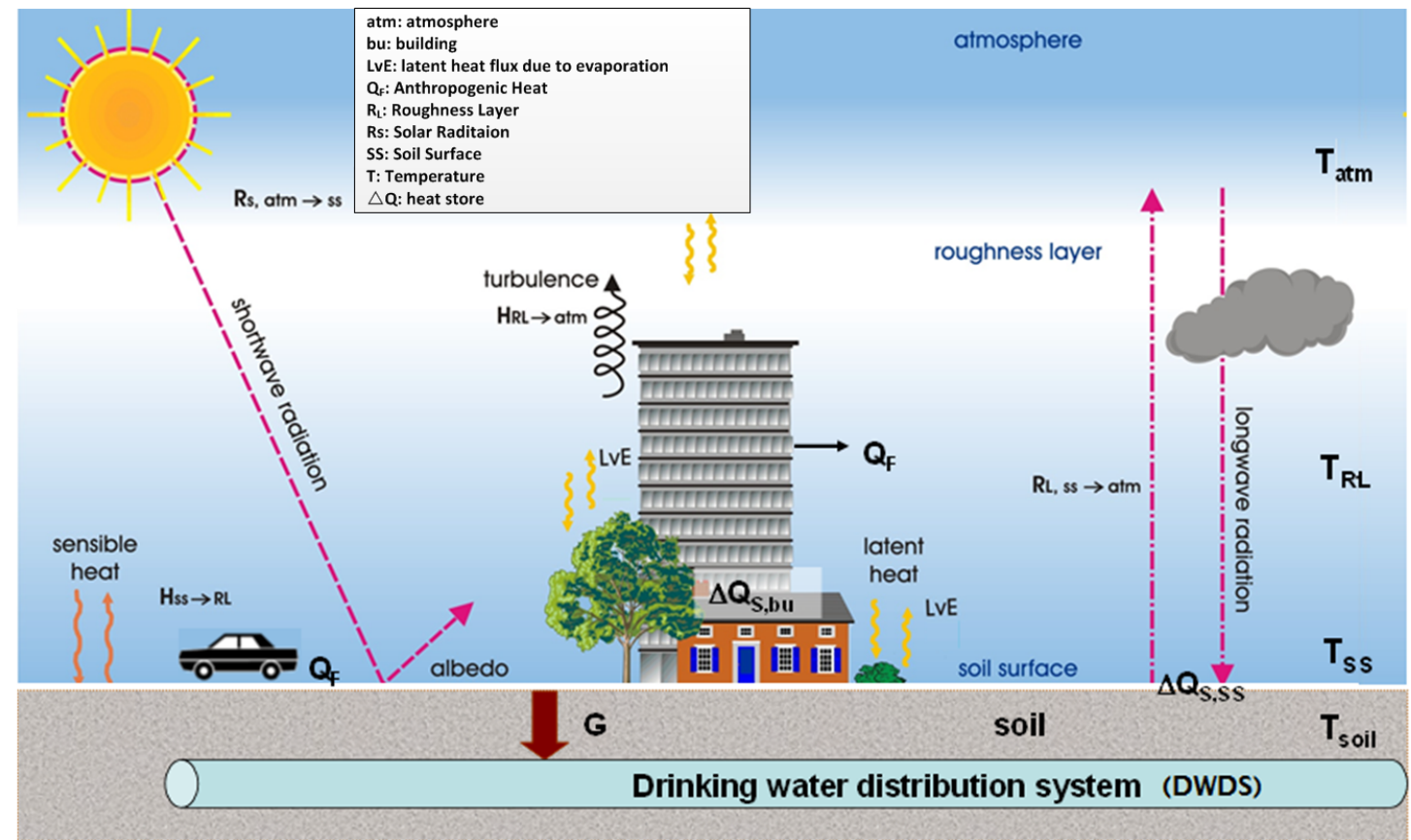

Figure 2. Schematic heat transfer in an urban setting (following Blokker and Pieterse-Quirijns, 2013).

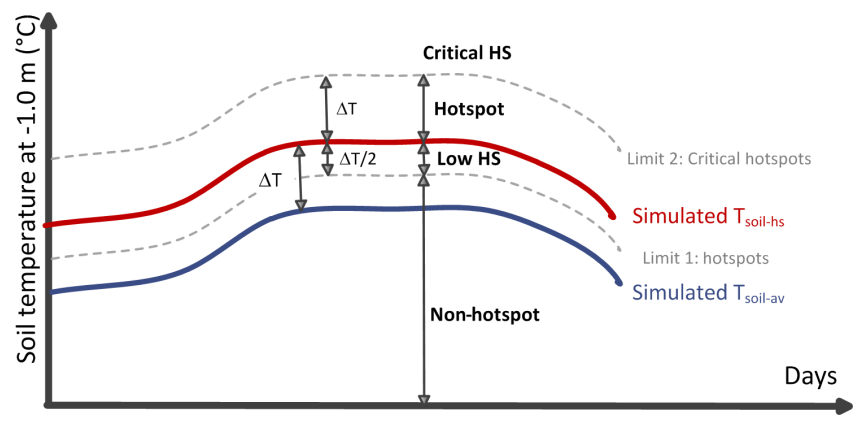

Figure 3. Schematic representation of the hotspot categories.

for instance during a heat wave, and coarse spatial resolution can cause local variations at smaller scales (e.g. $10 \mathrm{~m} \times 10 \mathrm{~m}$ ) to be missed.

Anthropogenic heat sources are found not only above ground, but also under ground, e.g. sewers or district heating systems, as shown by a number of German studies focusing on the subsurface urban heat island (SSUHI; Benz et al., 2015; Menberg et al., 2013a). Blokker and PieterseQuirijns (2013) developed a micrometeorology model to pre$\operatorname{dict} T_{\text {soil }}$ at various depths as a function of weather and environmental conditions. Agudelo-Vera et al. (2015a) extended the model by adding anthropogenic heat sources using literature values reported by Stewart and Oke (2012). Simulations performed by Agudelo-Vera et al. (2015a) showed that high $Q_{F}$ significantly influences the $T_{\text {soil }}$ at $1 \mathrm{~m}$ in depth. The results of the measurements of the temperatures at the tap also suggest that the SSUHI varies within the city and that there are also so-called "hotspots" in the underground (AgudeloVera et al., 2015a). Therefore, different areas in the city have different probabilities of exceeding the threshold temperature. Although the average city and the peri-urban neighbourhoods show a low probability of exceeding the temperature limit, the hotspots show a higher probability in the current situation, and even more in the future. Identifying the location of the hotspots and quantifying their intensity are crucial in reducing the probability of exceeding the temperature limit. SSUHI is a dynamic phenomenon that has to be specified in location and time. Therefore a more detailed analysis is needed, for instance at a resolution of $10 \mathrm{~m} \times 10 \mathrm{~m}$ and on a daily basis. To comply with the current legislation in the Netherlands, new methods and tools are needed to assess anthropogenic heat sources that influence the temperature in the distribution mains and to monitor and predict drinking water temperature in the network at small spatial scales.

Currently different sources of data and tools are available: (i) records of measurements of the water temperature at the tap for several years, (ii) meteorological data and models to determine the soil temperature and (iii) GIS information on the location of different infrastructures and urban characteristics. However, the sources and the locations in the city with relatively high soil temperatures are still unknown. The objective of this article is to find a method, based on available information and tools, to identify heat sources and urban characteristics that locally influence the soil temperature at $-1.0 \mathrm{~m}$ on a small spatial scale. Finding the location of anthropogenic sources and their influence on $T_{\text {soil }}$ will support 
Table 2. Additional input data for the soil temperature model (source: Agudelo-Vera et al., 2015a).

\begin{tabular}{llrrr}
\hline Variable & Definition & Unit & Average city & Hotspots \\
\hline$\alpha$ & thermal diffusion coefficient & $10^{-6} \mathrm{~m}^{2-1}$ & 0.6 & 1.3 \\
$z_{0}$ & roughness length & $\mathrm{m}$ & 0.95 & 0.95 \\
$Q_{F}$ & anthropogenic heat & $\mathrm{W} \mathrm{m}^{-2}$ & 100 & 150 \\
$a_{1}^{*}$ & empirical coefficient & - & 0.8 & 0.8 \\
$a_{2}^{*}$ & empirical coefficient & $\mathrm{s}$ & 30 & 42 \\
$-a_{3}^{*}$ & empirical coefficient & $\mathrm{W} \mathrm{m}^{-2}$ & 100 & 120 \\
\hline$\alpha=\lambda_{\text {soil }} / \rho_{\text {soil }} \cdot C_{p}$, where $\lambda_{\text {soil }}$ is thermal conductivity $\left(\mathrm{W} \mathrm{m} \mathrm{K}^{-1}\right), \rho_{\text {soil }}$ is soil density $\left(\mathrm{kg} \mathrm{m}^{-3}\right)$ and $C_{p}$ is soil \\
heat capacity $\left(\mathrm{J} \mathrm{kg}^{-1} \mathrm{~K}^{-1}\right){ }^{*} a_{1}, a_{2}$, and $a_{1}$ values are fitted using data of measurements conducted in 2012.
\end{tabular}

the selection of site-specific mitigation or adaptation measures. This information can also be used during the planning phase for installation/replacement of pipelines to determine optimal location (not only $x$ and $y$ coordinates, but also depth), considering the existing urban infrastructure and potential increase in temperature due to climate change.

\section{Method}

This paper introduces a method to identify heat sources and urban characteristics that locally influence the soil temperature (Fig. 1). The proposed method is based on available data and tools. Table 1 summarises the existing approaches to monitor or determine the temperature at the drinking water distribution.

The proposed method (Fig. 1) combines measurements and simulations of soil and water temperature and mapping of urban anthropogenic heat sources to better understand $T_{\text {soil }}$ in cities. The three methods described in Table 1 are coupled. First, a retrospective analysis of soil temperatures and water temperatures is performed to determine the typical range of variation. Second, spatial relationships were investigated using the data of the temperature at the tap and the GIS information of potential heat sources and solar radiation. Finally, measurements were used to validate the simulated temperatures and to validate the effect of the anthropogenic sources on the soil temperature.

\subsection{Retrospective analysis}

\subsubsection{Soil temperature simulations}

The model developed by Blokker and PieterseQuirijns (2013) and extended by Agudelo-Vera et al. (2015a) was used to simulate the urban $T_{\text {soil }}($ Fig. 2). The extended model describes (i) the heat transfer in the roughness layer (RL), which is driven by the sensible heat fluxes between the atmosphere and the RL and (ii) the heat transfer between the soil surface (SS) and roughness layer (RL; $H_{\mathrm{SS} \rightarrow \mathrm{RL}}$ ). The energy balance between the RL and the atmosphere was kept from the original model, while the heat balance in the soil surface was complemented with anthropogenic heat emissions $\left(Q_{F}\right)$ and heat storage in the urban environment $\left(\Delta Q_{\mathrm{s}}\right)$; see Eq. (1).

$$
\begin{aligned}
\rho_{\text {soil }} C_{p, \text { soil }} \frac{\partial T_{\text {soil }}}{\partial t}=\lambda_{s} \frac{\partial^{2} T_{\text {soil }}}{\partial z_{s}^{2}}+\frac{1}{\Delta z} \\
\left(R_{\text {net }}+Q_{F}-\Delta Q_{\mathrm{s}}-\mathrm{LvE}-\rho C_{p}\left(T_{\mathrm{SS}}-T_{\mathrm{RL}}\right) / \mathrm{Rg}\right),
\end{aligned}
$$

in which $\rho_{\text {soil }}\left(\mathrm{kg} \mathrm{m}^{-3}\right)$ is the soil density, $C_{p \text {,soil }}$ $\left(\mathrm{J} \mathrm{kg}^{-1} \mathrm{~K}^{-1}\right)$ is the soil heat capacity, $R_{\text {net }}\left(\mathrm{W} \mathrm{m}^{-2}\right)$ is the net radiation, $\Delta Q_{\mathrm{s}}\left(\mathrm{W} \mathrm{m}^{-} \mathrm{m}^{-3}\right)$ is the heat storage on the surface and in above-ground urban elements $\left(\mathrm{W} \mathrm{m}^{-2}\right)$ and $\mathrm{LvE}$ is the latent heat flux due to evaporation $\left(\mathrm{W} \mathrm{m}^{-2}\right)$. $\mathrm{LvE}$ from each surface is calculated with the modified version for urban areas of the Penman-Monteith equation (Grimmond and Oke, 1991) and using empirical values defined by Berthier et al. (2006) and Järvi et al. (2011). A detailed description of the equations is given in Agudelo-Vera et al. (2015a). The heat storage flux is the net uptake or release of energy from an urban system. All surfaces and objects in an area absorb or release energy. The storage heat flux $\Delta Q_{\mathrm{s}}\left(\mathrm{W} \mathrm{m}^{-2}\right)$ has been parameterised by Grimmond and Oke (1999, Eq. 2):

$\Delta Q_{\mathrm{s}}=a_{1} R_{\mathrm{net}}+a_{2} \frac{\partial R_{\mathrm{net}}}{\partial t}+a_{3}$,

where $a_{1}(-), a_{2}(\mathrm{~s})$ and $a_{3}\left(\mathrm{~W} \mathrm{~m}^{-2}\right)$ are empirical coefficients for different surface types. Values of these coefficients are given in Grimmond and Oke (1999) and Roberts et al. (2006).

The model uses hourly meteorological data from the Royal Dutch Meteorological Institute (KNMI, 2016). The input time series are air temperature, relative humidity, global radiation, precipitation, wind speed and cloudiness. The anthropogenic sources are simulated using a constant value. For this study the city of Rotterdam was used as a case study. For Rotterdam the model has been calibrated for the summer condition (Agudelo-Vera et al., 2015a). $T_{\text {soil }}$ at $-1.0 \mathrm{~m}$ in the peri-urban areas, the average city and in the hotspots were simulated using the extended soil temperature model. The soil density and the soil thermal properties change with soil moisture. Soil moisture changes over time due to evaporation and rainfall, but also due to groundwater management 
Table 3. Overview of the urban characterisation and heat sources that influence the soil temperature.

\begin{tabular}{|c|c|c|c|c|c|c|c|}
\hline \multirow{2}{*}{\multicolumn{2}{|c|}{$\begin{array}{l}\text { Characteristics } \\
\text { Shade condition }\end{array}$}} & \multicolumn{6}{|c|}{ Examples } \\
\hline & & \multicolumn{2}{|c|}{ No Shade } & \multicolumn{2}{|l|}{ Partial shade } & \multicolumn{2}{|l|}{ Shade } \\
\hline \multicolumn{2}{|l|}{ Urban type } & \multicolumn{2}{|c|}{ Industrial } & Residential & Urban square & \multicolumn{2}{|l|}{ Park } \\
\hline \multicolumn{2}{|l|}{ Top layer } & \multicolumn{3}{|c|}{ Concrete paving slabs } & \multicolumn{3}{|l|}{ Grass } \\
\hline \multirow[t]{2}{*}{$\begin{array}{l}\text { Anthropogenic } \\
\text { sources }\end{array}$} & Above ground & Hospital & $\begin{array}{l}\text { Laundry } \\
\text { facilities }\end{array}$ & $\begin{array}{l}\text { Reflection of } \\
\text { buildings }\end{array}$ & $\begin{array}{l}\text { Swimming } \\
\text { pool }\end{array}$ & $\begin{array}{l}\text { High density of } \\
\text { buildings }\end{array}$ & $\begin{array}{l}\text { Electrical distribution } \\
\text { substations }\end{array}$ \\
\hline & Under ground & Metro & High-power cables & ATES & Parking & \multicolumn{2}{|c|}{ District heating systems } \\
\hline
\end{tabular}

(a)

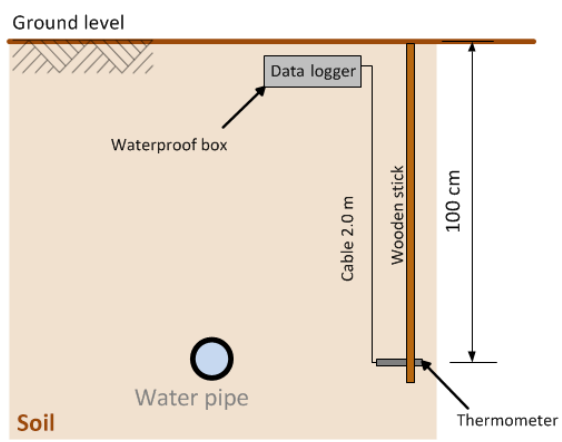

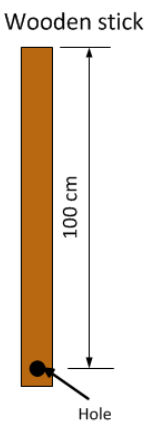

(b)

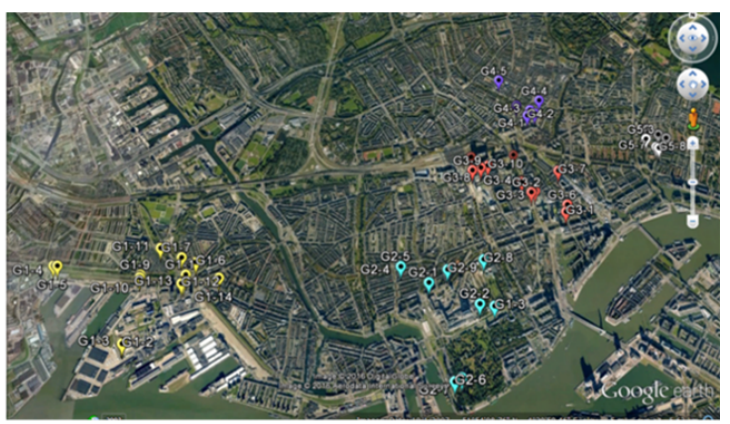

Figure 4. (a) Detail of the soil temperature measurement installation and (b) locations of the measurements (source: Google Earth).

or due to leaks from the sewer or drinking water networks. However, the model has been validated for the summer, when soils are often dry and there is little precipitation. Under these conditions fixed values for soil thermal conditions, anthropogenic heat and heat storage can be assumed. The input data reported by Blokker and Pieterse-Quirijns (2013) are used, plus the data reported in Table 2.

$Q_{F}$ sources heat the urban atmosphere by conduction, convection, and radiation. The contribution of $Q_{F}$ to the urban energy balance is largely a function of latitude and season of the year. $Q_{F}$ has been reported to range from tens to hundreds of $\mathrm{Wm}^{-2}$ in US and European cities (Sailor and Fan, 2004; Pigeon et al., 2007) and as high as $1590 \mathrm{Wm}^{-2}$ for the business district of Tokyo (Ichinose et al., 1999). Agudelo-Vera et al. (2015a) calibrated the model for Rotterdam using a single $Q_{F}$ value in the atmosphere: for the average city, $100 \mathrm{Wm}^{-2}$, and, for the hotspots, $150 \mathrm{~W} \mathrm{~m}^{-2}$.

\subsubsection{Retrospective analysis of measurements of the water temperature at the tap}

$T_{\text {soil }}$ at $-1.0 \mathrm{~m}$ in the average city and in the hotspots were simulated using the extended soil temperature model (Agudelo-Vera et al., 2015a). The expected maximum daily $T_{\text {soil }}$ for the average city $\left(T_{\text {soil-av }}\right)$ and the maximum expected daily $T_{\text {soil }}$ for the hotspots $\left(T_{\text {soil-hs }}\right)$ were determined from simulations. A period of 16 years was simulated (2000$2015)$ to identify inter-annual variations. Temperature measurements from 2008 to 2015 at the tap ( $\left.T_{\text {tap }}\right)$ during the sum- mer were used. $T_{\text {tap }}$ measurements were then classified into four categories, using $T_{\text {soil }}$ simulations, as described in Fig. 3.

Next, the tap temperatures were plotted and assigned to the closest DWDS pipe segment. Additional spatial information from anthropogenic heat sources (from step 1) in the city was also collected and plotted. Data from the location of the DWDS were analysed together with the information regarding the height of the buildings. Using a GIS tool, the solar radiation onto each pipe was determined. Additionally, the hotspots identified from the $T_{\text {tap }}$ measurements and the potential heat sources were plotted. Proximity analyses were used to determine the relationship between the heat sources and the four hotspot categories. Areas with a high density of hotspots were identified to narrow down the search. For these specific locations a measurement set-up was proposed to validate the hypotheses.

\subsection{GIS analysis: identification of the urban characteristics and heat sources}

Potential factors or heat sources that can influence $T_{\text {soil }}$ were identified based on the scientific literature (Menberg et al., 2013b; Revesz et al., 2016) and practical experience of representatives of the Dutch drinking water companies (Table 3). The factors and heat sources are categorised: aboveground or underground. The factors above ground are no or little shade, high density of buildings and/or reflection of building facades, waste heat of specific buildings or infrastructure. Factors underground are district heating systems, buried high- 
(a)

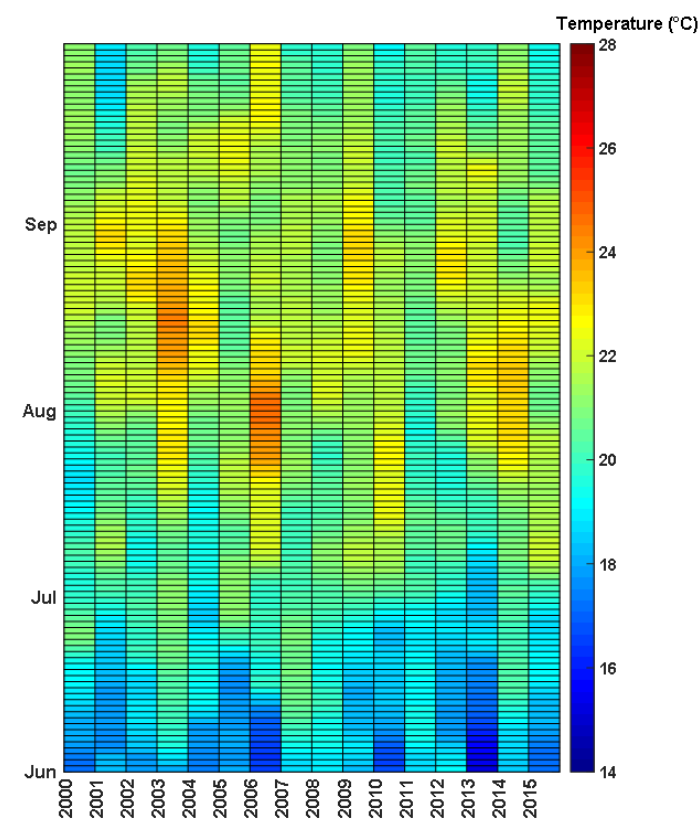

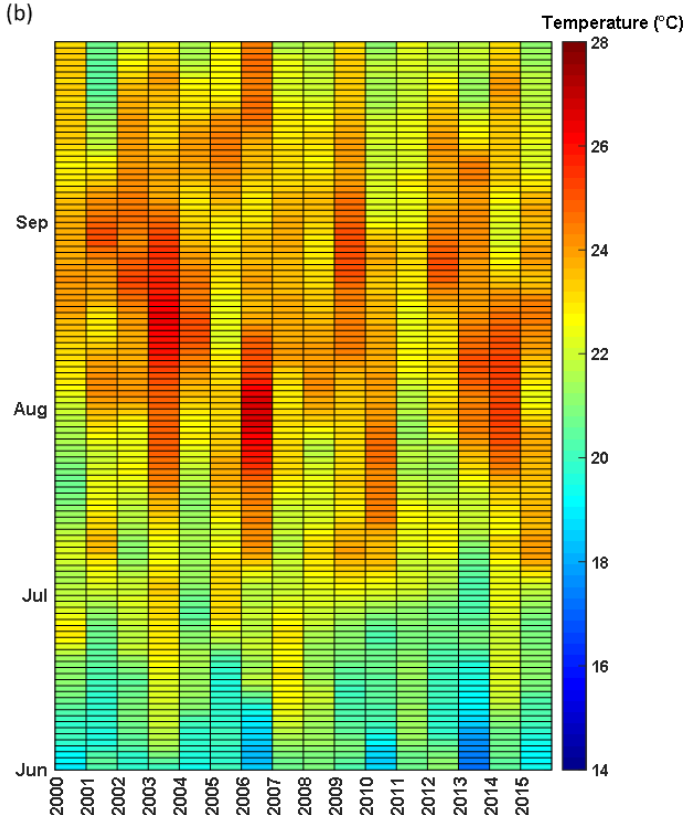

Figure 5. Simulations of $T_{\text {soil }}$ at $-1.0 \mathrm{~m}$ in the average city (a) and in the hotspots (b) from 2000 until 2015 during the months June, July, August and September.

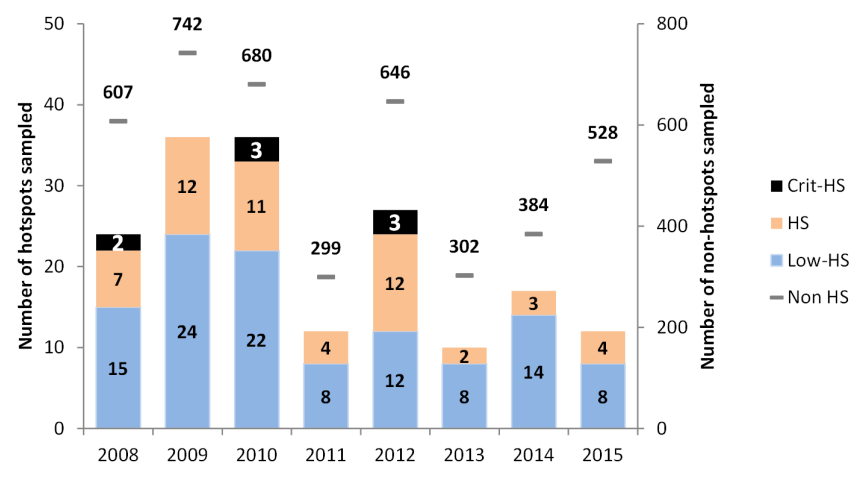

Figure 6. Overview of the categorisation of the measurements of the water temperature at the tap per year (HS: hotspot).

power cables, basements/underground parking facilities, tunnels (metro infrastructure), sewer networks, aquifer thermal storage (ATES) systems and underground heat storage infrastructure. For the GIS analysis, the anthropogenic heat sources were mapped. Then, the solar radiation in each pipe location was determined using data from the location of the DWDS and the height of the buildings using ArcGIS. Finally the spatial relationship between the $T_{\text {tap }}$ and the heat sources and solar radiation was also analysed with ArcGIS for 1 July 2016 per square metre.

\subsection{Soil temperature measurement plan in Rotterdam}

$T_{\text {soil }}$ measurements were conducted in Rotterdam. The measurement locations were selected based on the location of the selected anthropogenic sources (Table 3), and the expert knowledge of two representatives of drinking water company Evides in Rotterdam. Details of the $T_{\text {soil }}$ measurement installation are given in Fig. 4a. Based on the proximity to the heat sources identified in Table 3, 48 locations were selected to perform $T_{\text {soil }}$ measurements for almost 3 months (18 July until 9 October 2016): Fig. 4b.

\section{Results and discussion}

\subsection{Retrospective analysis}

\subsubsection{Simulating $T_{\text {soil }}$ in the average city and in the hotspots}

Figure 5 shows $T_{\text {soil }}$ simulated for the months June, July, August and September between 2000 and 2016, for the average city and for the hotspots, using hourly meteorological data from the Royal Netherlands Meteorological Institute (KNMI, 2016). The simulations for the average city show $15^{\circ} \mathrm{C}<T_{\text {soil-av }}<25^{\circ} \mathrm{C}$, and, for the hotspots, $17^{\circ} \mathrm{C}<T_{\text {soil-hs }}<27^{\circ} \mathrm{C}$. The $25^{\circ} \mathrm{C}$ threshold temperature is approached only in very hot summers in the average city. In the hotspots the threshold is exceeded in 8 of the 16 simulated years, with a total of 75 days in 16 years. In a cold and wet year, 2011 , a maximum $T_{\text {soil-hs }}$ of $23^{\circ} \mathrm{C}$ was simulated. 


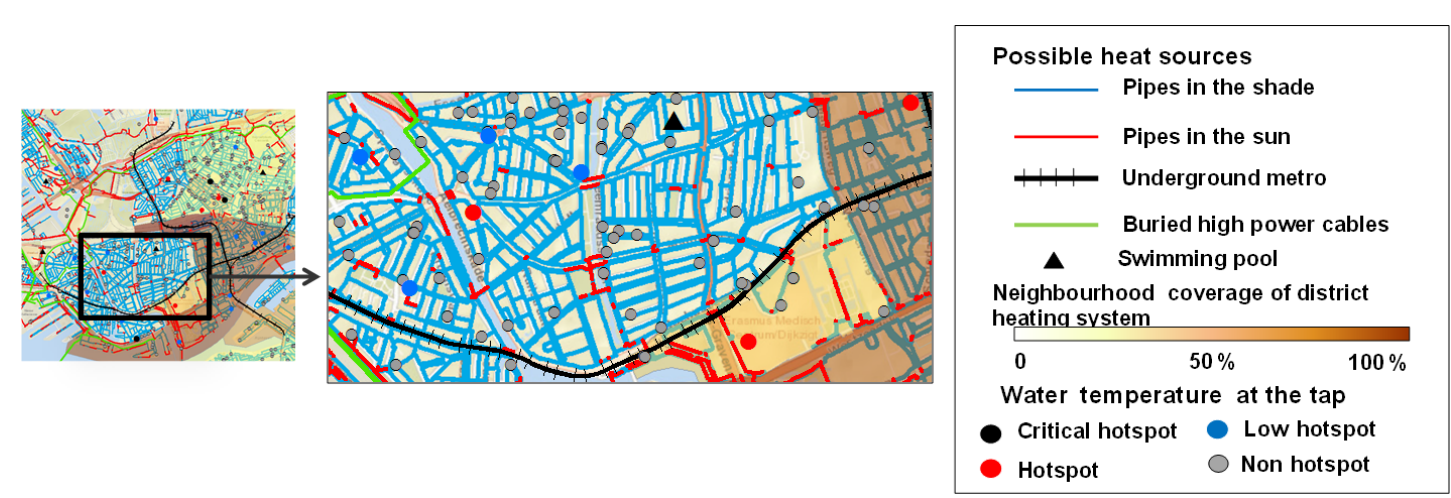

Figure 7. Detail of the GIS analysis for a small area of the case study.

(a)

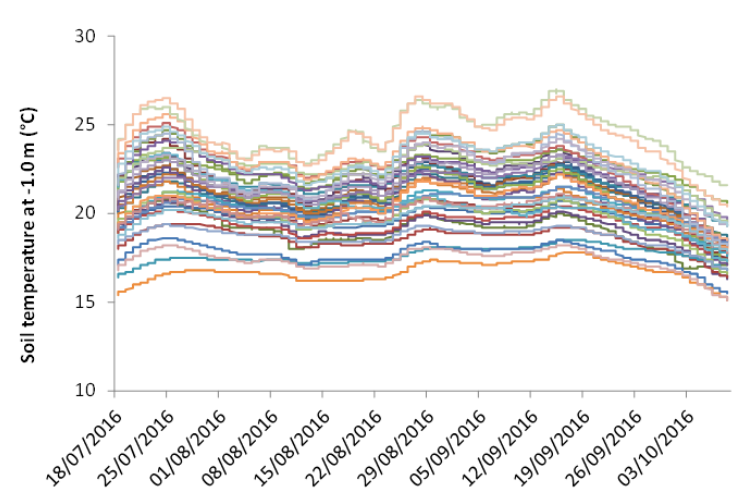

(b)

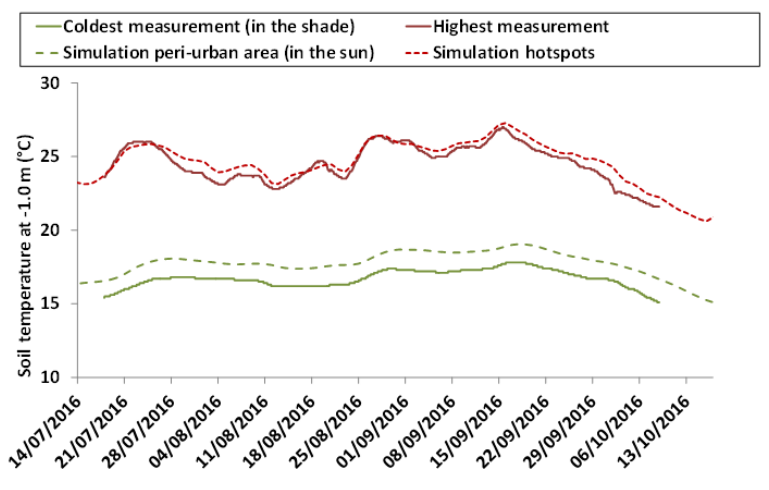

Figure 8. (a) Overview of the soil temperature of all 42 locations and (b) the range of the simulations and the measurements.

\subsubsection{Analysis of the measurements of the water temperature at the tap}

The measurements of the water temperature at the tap from 2008 until 2015 were categorised as non-hotspot, low hotspot, hotspot and critical hotspot. Figure 6 shows the results. The number of hotspots is relatively small compared with the number of non-hotspots. It is important to highlight that current sampling of the locations is random (in time and place) and not focused on finding the warmest locations.

\subsection{GIS analysis}

Figure 7 shows a detail of the GIS analysis results, plotting the possible heat sources and shade conditions. Locations with pipes completely in the sun, based on the GIS analysis, are easy to identify. Shade of the trees was not considered and therefore some pipes in urban parks seem to be in the Sun when they are in the shade. By plotting the different heat sources, the interactions and the proximity of the sources in some areas become evident. In this way areas with a busy underground can be identified. Mapping the categorisation of the measurements of the water temperature at the tap (critical hotspot, hotspot, low hotspot and non-hotspot) and making a
2-D spatial analysis with ArcGis did not provide a significant relationship. This can be explained by (i) the limited availability of measured hotspots, (ii) the 2-D analysis not considering the depth of the sources, (iii) possible issues with data resolution and quality and (iv) possible heat sources that are not yet identified.

\subsection{Soil temperature measurements}

The measurement set-up was successfully installed and run in 44 out of the 48 locations originally selected. In three locations there were concrete elements in the underground that did not allow the installation and in one location there were marble pavers that should not be removed. The thermometers were calibrated after the measurement period. Two thermometers suffered physical damage and they could not be calibrated. The results of the 42 remaining thermometers are shown in Fig. 8a. The autumn of 2016 was unusually warm in the Netherlands. Air temperatures above $30^{\circ} \mathrm{C}$ were recorded on 20 July, 24 and 25 August and 13 and 14 September. Considering the coldest location (in a park in the shade) as a reference, a maximum SSUHI $-1.0 \mathrm{~m}$ of $10^{\circ} \mathrm{C}$ between the locations was measured. Specific relations with re- 
spect to a single source cannot be inferred due to the limited number of locations per anthropogenic source. In this study 11 anthropogenic heat sources, 2 soil cover types, 4 urban types and variable shade conditions were selected to monitor $T_{\text {soil }}$ at $-1.0 \mathrm{~m}$. The results showed a SSUHI $-1.0 \mathrm{~m}$ of ca. $10^{\circ} \mathrm{C}$, during a hot period, which confirms the heat stress in the shallow urban underground.

Moreover, the large spreading of the measured soil temperatures confirms that the SSUHI varies within the city. Preliminary analysis of the measurements showed that the most significant indicators of the presence of a hotspot are no shade, concrete paving slabs as a top layer and the presence of at least one anthropogenic heat source (Agudelo-Vera, 2017). Figure $8 \mathrm{~b}$ shows $T_{\text {soil }}$ simulated for the months June, July, August and September 2016 for the average city and for the hotspots. The simulated range shows a good agreement with the measured $T_{\text {soil }}$, which validates the results of the model.

\subsection{Discussion of the proposed method and future research}

Given the complexity and heterogeneity of urban soils and the unknown interactions of buried infrastructure in the city, finding the hotspots in the city needs a combination of various approaches, for example, modelling $T_{\text {soil }}$ temperatures, using alternative data sources, e.g. temperature at customer's taps and performing GIS analysis of shades of buildings and of the proximity between potential sources. Combining different methods proved to be a feasible way of determining and validating the typical range of variation of the urban $T_{\text {soil }}$ at $-1.0 \mathrm{~m}$, which is between 15 and $27^{\circ} \mathrm{C}$ during the summer over the last 16 years. However, the exact location cannot be determined yet. In this case study, the influence of several variables was monitored simultaneously: (i) heat sources, (ii) urban characteristics and (iii) solar radiation. Several locations were in the vicinity of two of more (nonequidistant) heat sources. This does not allow the identification of the most important sources. A more detailed analysis and monitoring of single sources are needed. A 3-D GIS analysis is recommended as a next step. For further research, it is recommended to monitor locations in the proximity of a single anthropogenic heat source to avoid interference between heat sources, for instance district heating systems and high-power cables.

This research focused on the Netherlands, with a moderate maritime climate with cool summers and mild winters. A similar approach can be used to identify hotspots in cities worldwide. Earlier research has shown that it is possible to use weather forecast information as an "early warning system" to predict temperature in the DWDS from changes in weather and climate (Agudelo-Vera et al., 2015b). Understanding the spatial distribution of anthropogenic heat sources and using models to simulate $T_{\text {soil }}$ will help managers to more specifically anticipate extreme weather events such as heat waves.

\subsection{Outlook}

Today the probability of exceeding the threshold temperature is still low. This probability is expected to increase with climate change, increasing urbanization and increasing pressure on the underground. Therefore, it is important to be able to anticipate and take measures to avoid the creation of new hotspots, to control current ones or to avoid hotspot locations when installing drinking water pipes. Determining $T_{\text {soil }}$ in urban areas is important for different infrastructures, for instance, to predict performance, e.g. pavement durability (Diefenderfer et al., 2006), coupled heat pumps (Garcia Gonzalez et al., 2012) and district heating systems (De Pasquale et al., 2017) and to determine the drinking water temperature (Blokker and Pieterse-Quirijns, 2013). Managers of a specific infrastructure cannot by themselves implement the required measurements that often involve urban planning. Collaboration between urban planners and infrastructure managers is crucial to create climate-change-proof cities. While mitigation measures can reduce the impact of the SSUHI and climatic change, these measures take time to implement and to have an impact. In the meantime, there is a need to consider drinking water temperature in the DWDS and prevent drinking water quality problems during heat waves, especially in the high-density urban areas.

In busy urban areas, congested with (underground) infrastructures, several anthropogenic heat sources can be overlooked during urban planning strategies to cope with climate change. These anthropogenic sources affect not only the air temperature, but also the soil temperature locally. Therefore, to achieve climate-change-proof cities, the urban configuration above and below the surface and climate change have to be included. This paper contributes to a better understanding of the SSUHI. With the presented method the range of SSUHI can be determined; adaptations from 2-D to 3-D GIS analysis and more directed sampling and the tap and soil measurements will allow one to localise the hotspots. Models are now based on constant values of anthropogenic sources. Temperatures of district heating systems and high-voltage cables can have seasonal patterns.

\section{Conclusions}

The subsurface heat island effect can be modelled using a soil temperature model that uses as input meteorological data and anthropogenic heat values. Finding the locations in the city with a higher SSUHI needs a combination of approaches, e.g. modelling $T_{\text {soil }}$ temperatures, performing GIS analysis of shade and reflections of buildings and performing soil temperature measurements. The proposed method proved to be useful for determining and validating the range of the typical urban shallow soil temperature during the summer. Further research is needed to determine the exact locations of the hotspots. The analysis verified the underground heat stress in 
the city due to a combination of exposure to solar radiation, anthropogenic heat sources and type of top layer.

Data availability. The data set is available as a Supplement.

\section{The Supplement related to this article is available online at https://doi.org/10.5194/dwes-10-83-2017-supplement.}

Competing interests. The authors declare that they have no conflict of interest.

Special issue statement. This article is part of the special issue "Computing and Control for the Water Industry, CCWI 2016". It is a result of the 14th International CCWI Conference, Amsterdam, the Netherlands, 7-9 November 2016.

Acknowledgements. The authors would like to thank Dutch water company Evides for their collaboration to perform this study.

Edited by: Edo Abraham

Reviewed by: four anonymous referees

\section{References}

Agudelo-Vera, C.: Hotspots in het leidingnet, BTO 2017.023, KWR, Nieuwegein, the Netherlands, 2017.

Agudelo-Vera, C., Blokker, M., van der Wielen, P., Raterman, B., and Dorland, E.: Drinking water temperature in future urban areas, BTO report; BTO 2015.012, KWR, Nieuwegein, 2015a.

Agudelo-Vera, C. M., Blokker, E. J. M., and Pieterse-Quirijns, E. J.: Early warning system to forecast maximum temperature in drinking water distribution systems, J. Water Supply Res. T., 64, 496-503, https://doi.org/10.2166/aqua.2014.040, 2015 b.

Benz, S. A., Bayer, P., Menberg, K., Jung, S., and Blum, P.: Spatial resolution of anthropogenic heat fluxes into urban aquifers, Sci. Total Environ., 524-525, 427-439, https://doi.org/10.1016/j.scitotenv.2015.04.003, 2015.

Berthier, E., Dupont, S., Mestayer, P. G., and Andrieu, H.: Comparison of two evapotranspiration schemes on a sub-urban site, J. Hydrol., 328, 635-646, 2006.

Blokker, E. J. M. and Pieterse-Quirijns, I.: Modeling temperature in the drinking water distribution system, AWWA, 105, E19-E28, https://doi.org/10.5942/jawwa.2013.105.0011, 2013.

De Pasquale, A. M., Giostri, A., Romano, M. C., Chiesa, P., Demeco, T., and Tani, S.: District heating by drinking water heat pump: Modelling and energy analysis of a case study in the city of Milan, Energy, 118, 246-263, https://doi.org/10.1016/j.energy.2016.12.014, 2017.

Diefenderfer, B. K., Al-Qadi, I. L., and Diefenderfer, S. D.: Model to predict pavement temperature profile: Development and validation, J. Transp. Eng.-ASCE, 132, 162-167, 2006.
Garcia Gonzalez, R., Verhoef, A., Vidale, P. L., Main, B., Gan, G., and $\mathrm{Wu}, \mathrm{Y}$.: Interactions between the physical soil environment and a horizontal ground coupled heat pump, for a domestic site in the UK, Renew. Energ., 44, 141-153, 2012.

Grimmond, C. S. B. and Oke, T. R.: An evapotranspirationinterception model for urban areas, Water Resour. Res., 27, 1739-1755, 1991.

Grimmond, C. S. B. and Oke, T. R.: Heat storage in urban areas: Local-scale observations and evaluation of a simple model, J. Appl. Meteorol., 38, 922-940, 1999.

Grimmond, C. S. B., Roth, M., Oke, T. R., Au, Y. C., Best, M., Betts, R., Carmichael, G., Cleugh, H., Dabberdt, W., Emmanuel, R., Freitas, E., Fortuniak, K., Hanna, S., Klein, P., Kalkstein, L. S., Liu, C. H., Nickson, A., Pearlmutter, D., Sailor, D., and Voogt, J.: Climate and more sustainable cities: Climate information for improved planning and management of cities (Producers/Capabilities Perspective), Procedia Engineering Sciences, 1, 247-274, 2010.

Ichinose, T., Shimodozono, K., and Hanaki, K.: Impact of anthropogenic heat on urban climate in Tokyo, Atmos. Environ., 33, 3897-3909, 1999.

Järvi, L., Grimmond, C. S. B., and Christen, A.: The Surface Urban Energy and Water Balance Scheme (SUEWS): Evaluation in Los Angeles and Vancouver, J. Hydrol., 411, 219-237, 2011.

Klok, L., Zwart, S., Verhagen, H., and Mauri, E.: The surface heat island of Rotterdam and its relationship with urban surface characteristics, Resources, Conserv. Recycling, 64, 23-29, 2012.

KNMI: Koninklijk Nederlands Meteorologisch Instituut Hourly information from KNMI stations, available at: https://www.knmi.nl/nederland-nu/klimatologie/uurgegevens (last access: 1 July 2017), 2016.

Menberg, K., Bayer, P., Zosseder, K., Rumohr, S., and Blum, P. Subsurface urban heat islands in German cities, Sci. Total Environ., 442, 123-133, 2013a.

Menberg, K., Blum, P., Schaffitel, A., and Bayer, P.: Longterm evolution of anthropogenic heat fluxes into a subsurface urban heat island, Environ. Sci. Technol., 47, 9747-9755, https://doi.org/10.1021/es401546u, 2013b.

Pigeon, G., Legain, D., Durand, P., and Masson, V.: Anthropogenic heat release in an old European agglomeration (Toulouse, France), Int. J. Climatol., 27, 1969-1981, 2007.

Revesz, A., Chaer, I., Thompson, J., Mavroulidou, M., Gunn, M., and Maidment, G.: Ground source heat pumps and their interactions with underground railway tunnels in an urban environment: A review, Appl. Therm. Eng., 93, 147-154, https://doi.org/10.1016/j.applthermaleng.2015.09.011, 2016.

Rijksoverheid: Drinkwaterbesluit, available at: http://wetten. overheid.n1/BWBR0030111/geldigheidsdatum_30-06-2017 (last access: 30 June 2017), 2011.

Roberts, S. M., Oke, T. R., Grimmond, C. S. B., and Voogt, J. A.: Comparison of four methods to estimate urban heat storage, $\mathrm{J}$ Appl. Meteorol. Climatol., 45, 1766-1781, 2006.

Sailor, D. J. and Fan, H.: The importance of including anthropogenic heating in mesoscale modeling of the urban heat island, B. Am. Meteorol. Soc., 397-403, 2004.

Stewart, I. D. and Oke, T. R.: Local climate zones for urban temperature studies, B. Am. Meteorol. Soc., 93, 1879-1900, 2012.

Versteegh, J. F. M. and Dik, H. H. J.: The quality of drinking water in the Netherlands in 2006, RIVM, 2007 (in Dutch). 